Volume 10, Issue 4, July-August 2019, pp.182-195, Article ID: IJM 1004018

Available online at http://iaeme.com/Home/issue/IJM?Volume $=10 \&$ Issue $=4$

Journal Impact Factor (2019): 9.6780 (Calculated by GISI) www.jifactor.com

ISSN Print: 0976-6502 and ISSN Online: 0976-6510

C IAEME Publication

\title{
THE APPLICATION OF QUALITY ASSURANCE CRITERIA IN LIGHT OF GOVERNANCE PRINCIPLES (THE MIDDLE EAST UNIVERSITY AS A MODEL)
}

\author{
Mohammad M. Al Helih \\ Faculty of Educational Sciences, Middle East University, Jordan \\ Tamara Yacoub Nasereddin \\ Faculty of Law, Middle East University, Jordan
}

\begin{abstract}
The purpose of the research is to determine the application of quality assurance standards in the light of the principles of governance (Middle East University as a model) in order to ensure the quality of operations and outputs by answering the following questions: What is meant by Universities governance and how the Middle East University has made governance their own quality. The importance of implementing the principles of governance and quality assurance standards has been identified in creating an integrated interactive environment through which the quality of guaranteed processes and products is ensured by demonstrating how governance and its principles work on the interconnectivity of inputs in order to ensure the quality of processes and thus outputs. The researchers recommended that quality assurance standards be addressed in their general framework and the interaction between these standards on the one hand and inputs on the other, so that governance and its principles are the interaction between standards.
\end{abstract}

Key words: Quality assurance, Quality assurance criteria, Governance, Governance principles, MEU.

Cite this Article: Mohammad M. Al Helih, Tamara Yacoub Nasereddin, The Application of Quality Assurance Criteria in Light of Governance Principles (The Middle East University as a Model), International Journal of Management, 10 (4), 2019, pp. $182-195$.

http://iaeme.com/Home/issue/IJM?Volume=10\&Issue $=4$

\section{INTRODUCTION}

The establishment of governance in the administration of university affairs will raise the educational and administrative systems at the university to a better level. University administration needs to change management more than change itself, because many of the requirements do not need to be modified by legal legislation, but to activate what exists, and 
apply it transparently within the policy of increasing achievement and monitoring performance, to move to the reform of university education through a rational approach. Studies on the management of the university concluded the importance of its application to improve the performance of the universities and ensure the quality of operations and outputs to reach the first place in the classification of international universities. University governance issues stem from the use of transparency, integrity, participation, clarity, regulations, instructions and accountability to develop and build communities, make positive changes in these universities, and prepare generations to deal with knowledge and technical explosion and meet the needs of their communities. In the context of the orientation towards governance and its potential impact on the higher education departments, especially with regard to the consideration of the concepts of competitiveness in open markets, and what will be imposed by this phenomenon of mechanisms to implement the standards to ensure the quality of these institutions and programs and products, not only at the national level but at the global level. Lack of attention to the principles of governance in management and the quality of programs and institutions may lead to the marginalization of these institutions.

Since the relationship between the governance of institutions of higher education and quality assurance is a strong one, and institutions do not determine their quality in accordance with international standards, and their patterns are condemned to marginalization and enslavement under the law of survival of the fittest. Therefore, there is a need for global and local application of governance in the departments of the university, ensuring the interaction and integration of its principles and quality assurance standards adopted, to reach the outputs capable of meeting the requirements of comprehensive development [1]. Ensuring the quality of university education calls for the presence of university leaders based mainly on governance, represented by boards of directors, and the existence of systems and procedures to regulate, control and ensure the quality of education with high levels of responsibility and transparency. It is therefore essential that higher education institutions establish all conditions to improve the quality of their educational, research and community services through evaluation, and development processes, which are consistently practiced within the TQM concept and which positively reflect on the quality of their operations and products $[2,3]$.

Quality Assurance is a systematic procedural test of the University in order to measure its compliance with local and international standards ensure that the University is working to achieve its objectives, providing and strengthening the required infrastructure. This requires setting quality assurance goals and mechanisms, as well as spreading the culture of quality and development in these universities. This also requires universities to develop an internal quality management system, to provide an internal control system and to increase its readiness for external evaluation [4, 3]. In this regard, [5] referred to King Saud University's approach to building quality management system, which is from the first approach and deals with operations according to basic and subsidiary standards as well as results according to performance indicators and audit and evaluation methods. The second approach focuses on how to achieve the internal quality assurance of the University in order to comply with the legal basis. [6] The subject of quality assurance and standards and some difficulties faced by institutions of higher education in general and the United Arab Emirates in particular, and its impact on the quality of graduates of these institutions, this included a presentation of quality assurance standards in many countries of the world, their similarities and differences, the difficulties encountered the reasons for obtaining them, how they are disposed of, and the best practices that achieve quality of operations and results.

There are many areas of university administration, diversity and security are interrelated in different ways, influenced by them, all working to achieve the goals, and thus aims to establish the idea of commitment and culture. It is the idea of creating a wide range of educational and 
moral content. This is the first area of university administration. To achieve credibility and increase confidence, especially in the information and data published about the university. The reports of the managers of the control and auditing units are among the most important areas of governance and are reflected positively on the University's operations and outputs. This represents the second domain. The third area is represented by transparency and clarity. Governance is used as an instrument of enlightenment to shed light on the different aspects of the University, reducing confusion and uncertainty. The stronger the governance, the more effective it is, to improve transparency and clarity. It is not an end in itself, but a tool to reach the different goals of the university and its strategy. This represents the fourth area, while the fifth objective is to achieve justice and apply "principled equality". Governance in this area creates opportunities for all, which increases the sense of justice, equity and security, to eliminate the deficit, greed and corruption. The sixth area is the good governance of the university, where governance highlights this good, especially with regard to planning, organization, guidance and follow-up, thus increasing the efficiency of university administration, by setting specific objectives for each activity, identifying the operational programs necessary to achieve the objectives, and mobilizing resources and possibilities, necessary to implement these objectives. The seventh and last area is increasing efficiency and attention. Governance plays a very important role in making the university more effective, making it a promising future in many ways, including: ensuring quality of outputs, improving quality and gaining competitive advantages for graduates $[7,8]$.

\section{RESEARCH PROBLEM AND QUESTIONS}

His research problem is linked to the phenomenon of governance and quality assurance that have cast a shadow on all universities. This research deals with the MEU's experiment in integrating and interacting between the principles of governance and, the quality assurance criteria as a process that ensures the quality of operations and thus outputs. Thus, the topic of interaction and integration between the principles of governance institutions of higher education, which stems from the use of the concepts of transparency, participation and accountability in the application of laws, regulations and university instructions and quality assurance criteria adopted at the university, with the aim of making positive changes and preparing generations that are able to cope with the knowledge and technical explosion, to meet the needs of their communities in the spirit of the times. This research has come to shed light on the experiment of the MEU in this field, by adopting governance as the basis for the application of quality assurance criteria in the university by answering the following two questions: What do we mean by university governance And How the MEU has made governance a prime anchor for applying quality criteria. The importance of the research comes from the importance of implementing the principles of governance and quality assurance criteria to create an integrated interactive environment through which to ensure the quality of outputs. The importance is therefore reflected in the following:

- This research is considered from the rare research, within the limits of the researchers' knowledge, which examined the integration and interaction between the principles of governance and quality assurance criteria in order to ensure the quality of outputs.

- It is hoped that the findings of this research will benefit academic and administrative leaders in the universities through their knowledge of the principles of governance and quality assurance criteria and their application in universities.

- It is hoped that the findings of this research will serve as a compass guiding the governing councils of universities and their administrative leaders, and accelerating the process of implementing its governance principles in conjunction with the implementation of quality assurance criteria and in each of its operations. 
- It is hoped that the researchers will develop a proposed framework for the implementation of the principles of governance in conjunction with the application of quality assurance criteria.

- It is hoped that this research will enrich the Arab library in the field of university governance and the application of quality assurance criteria.

\section{METHODOLOGY}

To achieve the objectives of the research, the descriptive methodology was used, to analyze the concept of governance, its principles, the quality assurance criteria and the basis of their application, and the predictive methodology, which aims to look into the future, by formulating a set of conditional predictions that outline the main features of university administration and the application of quality assurance criteria, from the present to the future, through the extraction of a proposed framework to ensure the quality of operations and thus outputs.

University governance is the application of criteria and systems of quality and excellence that govern the performance of universities, in order to achieve the integrity of trends and the health of behavior and interity of behaviors, and to ensure transparency, accountability and participation from all parties, and to give priority to the interests of the university to individual interests, which leads to the development of university performance and protect the interests of all parties directly and indirectly related to the university, down to the quality of processes and outputs [7]. The operational definition of university governance is how universities are managed and monitored by all parties, and thus serves as a tool to ensure the efficiency of the university administration and to take advantage of its resources, to ensure the quality of its operations and its outputs.

Quality assurance was defined by the Quality Assurance Agency (QAA) as a method to describe all the systems, criteria and materials used by the universities and educational institutions to maintain and improve criteria and quality criteria. This includes teaching, how students learn, scholarships and research [1]. The operational definition of quality assurance is the process of verifying that academic standards are consistent with the university's mission, and has been defined and achieved in accordance with the standards adopted by the accreditation of the Jordanian higher education institutions.

\section{ANSWER THE RESEARCH QUESTIONS}

\subsection{Answer the first question: What is university governance?}

The modern concept of governance was popular in the early 1970s in business and corporates in America and Britain, and then moved to universities because of their role in development from its different aspects: social, economic, administrative, political, health and others [9]. University operators strive to articulate the university's vision and mission, which later determine its strategic objectives. No matter how the formulas of visions and means differ, but they gather in one way or another, that the highest goals of the university are based on good education, represented by the payment of graduates who are eligible to fill vacancies in different state instructions in proportion to their needs. i.e., there is a harmony between the requirements of the society and the quality of the graduates and the scientific research which enhances the knowledge and generates it and meets the needs of the society and solves its problems, in addition to serving the society through the interaction between the university and the society and the contribution of the university in solving the different kinds of issues at all levels, through research and industrial, educational social, agricultural and other workshops $[10,11,12$ ]. University governance is defined as an integrated system consisting of a set of laws, regulations and instructions aimed at achieving the quality of operations outputs, academic and administrative bodies and distinguish those [13], through the selection of appropriate strategies 
to achieve the goals of the university. It is also an integrated and interactive human and physical elements that create harmony and balance within the university. Its loss causes a major imbalance in university operations. It is good management of the university to ensure the quality of its operations and then its outputs. It is a set of criteria, systems of quality and excellence that govern the performance of the universities. It applies the laws, legislations, regulations, instructions and criteria of excellence on all components of the university, on the basis of transparency, accountability and participation in the interest of the university, and protects the interests of all who have a relationship with them [14].

University governance has become a very important issue in the field of higher education, which is still facing radical changes in recent decades, including [14, 7]:

- Increased pressure on universities as social demand for higher education increases, and is associated with increasing population growth.

- The emergence of new programs of education provided by public and private universities as well as new patterns of education, such as e-learning, integrated learning and distance learning.

- Weak infrastructure and lack of opportunities for scientific research and weak culture in public and private sector institutions, and weak link between ongoing research projects and economic and social development plans.

- The target transformation of the role of the university from a teaching university depends on the indoctrination method to a new method is the research university.

- Reducing the negative phenomena that are growing in the Arab university education in general, such as the disturbing outbreak of student violence in universities, the low quality of graduates, the weakness of scientific research and its low level.

- The global classification has increased the pressure for the application of governance at universities. The global classification of major universities is linked to three related factors: concentration of talent, provision of finance and governance.

Thus, it is possible to say that university governance is an integrated bloc that creates a balance within the work that causes its loss a major imbalance in the university. For example, governance is shared by directors, professors, students and the surrounding social environment. The literature examined in governance has converged on three principals [14], [15]:

Transparency: It is the design of systems, mechanisms, policies and legislation and their application. It is one of the important international criteria in the classification and ranking of countries and even universities [13]. It is a mechanism for measuring the degree of application of governance in society, and allows individuals to acquire knowledge and information related to governance, so that they can make decisions that has a common effect [16]. Transparency in the governance of universities means clarity in the design and application of systems, mechanisms, legislation and tools that guarantee the right of each party to the university and the ease of flow of accurate and objective information and ease of use of employees and students [14].

Participation: is to provide the governing bodies with the opportunity of both academic and administrative bodies to participate in policy - making and work rules in different areas of university life [17]. Good governance includes all aspects of participation in the university's leadership and governance councils, and is a model in the implementation of its policies. Thus, participation in university governance means that citizens, individuals, students NGOs and faculty members have the opportunity to participate in policy - making, and establishing rules for work in various areas of life, especially government work [14].

Accountability: means enabling the relevant individuals within and outside the university to monitor the work without causing this to disrupt the work or harm others [17]. As well as, 
the application of the instructions and regulations with transparency to all employees and students [18]. Accountability is the other side of leadership, without which leadership is dictatorial [19]. It is a commitment that obliges others to account or answer the responsibility they are based on [20].

There are many areas of university governance, but they are interconnected with interactive loops that influence and affect each other, and work towards their goals and in a coherent way, to establish the idea of commitment and its culture, and achieve credibility, increase confidence, improve transparency and achieve clarity, and providing local and international investment attractions, and achieving justice and the application of the principle of equality and the good management of the university and increasing the effectiveness and interest $[21,17]$. In light of the above, university governance can be defined as a set of criteria, quality and excellence systems, that govern the performance of universities and to ensure transparency, participation and accountability.

\subsection{The second question: How the Middle East University has made governance a prime anchor for applying quality criteria?}

Quality assurance criteria are the elements and objectives that are controlled in light of the achievement of quality objectives. Criteria have entered various commercial and industrial fields in the last decade of the twentieth century, then developed to become educational institutions, including universities, are subject to the application of criteria and global measures to ensure the quality of education, and then quickly the various universities in many countries of the world to adopt the idea of quality in performance and the application of quality criteria and the services provided, and what they use until they reach their mission as effective educational institutions in society. Quality assurance criteria are a set of benchmarks for comparison and judgment that are used to set and evaluate achievement objectives and reflect the current levels of achievement at the university. These criteria may also be levels set by a third party or university level of achievement, and the educational system works like any other system according to a certain strategy takes into account the circumstances surrounding the system and the cultural structure within it, the organizational climate, the technical progress, the available physical and human resources, and the needs and desires of the public. Therefore, it is concerned that its outputs confirm to the international standards for quality control of production through the constant pursuit of the use of standards for quality measurement and control. In this regard, the Higher Education Accreditation Authority of Jordan seeks to improve the performance of Jordanian higher education institutions and enhance their competitiveness at the national, regional and international levels, and ensure the application of the criteria of accreditation and quality of Jordan and the development of criteria to ensure the continuity of quality and competitiveness [22]. In order to improve the performance of universities, the quality assurance criteria must be applied in order to improve the performance of the universities and to ensure the quality of their operations and thus their outputs and to obtain the national quality certificate, up to global quality certificate. This is done only by representing quality and adapting it and adopting the university governance and applying it in all the university operations through the reliance on the system of governance, and the fact that the governance of the universities is an integrated system of a group of human and physical elements integrated and interactive generate harmony and balance within the university. Its loss causes imbalance in its operations and hence its outputs ([7]; [14], such as:

- To take into account the criteria, principles, and powers contained in university governance, and to adopt and implement them in all quality assurance criteria.

- The application of the ethics of work and communication in all criteria of quality assurance, through a set of standards and behavioral controls that reinforce the principle of ethics and 
accountability in the decision - making and the establishment of programs based on obedience and ethics.

- Adopting quality systems, criteria and evaluation according to international and local standards, which include policies and practices and the adoption of internal and external evaluation.

- Establish a clear system of administrative and academic control that takes into account the principles of governance through the quality control and auditing unit.

- Respecting academic freedoms, activating the principles of the rights of students and faculty members, transparency, clarity, and fair treatment, and activating the structures of accountability, monitoring and evaluation on the basis of the new governance.

The university governance is one of the most important basic systems that aim at achieving total quality, quality of leadership, management and performance, quality of operations and outputs. Higher education in its institutions represents the appropriate ground for the application of its rules and principles. The United Kingdom's success in its application of governance in its universities, for example, has clearly contributed to the achievement of these universities in the universal classification of universities. Therefore, when applying governance and quality assurance criteria in universities, this should include all its components. But, universities don't apply to governance, this will negatively affect the rules and principles of governance, and the quality of its operations, its outputs, its leadership its administration, and its internal and external environment. This is confirmed by the following studies: [23, 24, 25, 26, and 27]. The implementation of quality assurance criteria has become a necessity to participate in the advancement of higher education globally and across borders and has led the movement of students and members of the teaching and administrative bodies to the challenges of existing quality assurance bodies and to recognize the qualifications. Quality measurement includes many evaluative activities that include the expression of quantitative and qualitative compliance with standards, definition of indicators, development of parameter systems, assessment tools., analysis and interpretation of results [28]; [29]. In the last years, there has been interest in questions about "What" and "Why" in terms of physical and human aspects in universities, and did not give sufficient attention to questions "How", which led to weak organizational structure and the weakness of the possibilities of performing the activities of evaluation at the university. [30] pointed out that the modern approach to quality assurance and criteria is concerned with the continuous improvement of quality rather than accountability, which focuses on the university proving that it works at a level equal to or higher than the minimum standards required. Determining the training needs of individuals and universities will usually help them meet and apply quality assurance systems [31]. Given the limited budgets of the universities, about how best to use them in building their capacities [32]. It is important to take advantage of the community's own development and to help build capacity for multilevel change for individuals, groups and universities, to be able to respond to changes constantly. Morrison (2005) believed that capacity - building is connected with the creation of a learning university, seeking to learn, and includes different levels including all the physical and human components of the university as shown in Figure (1). 


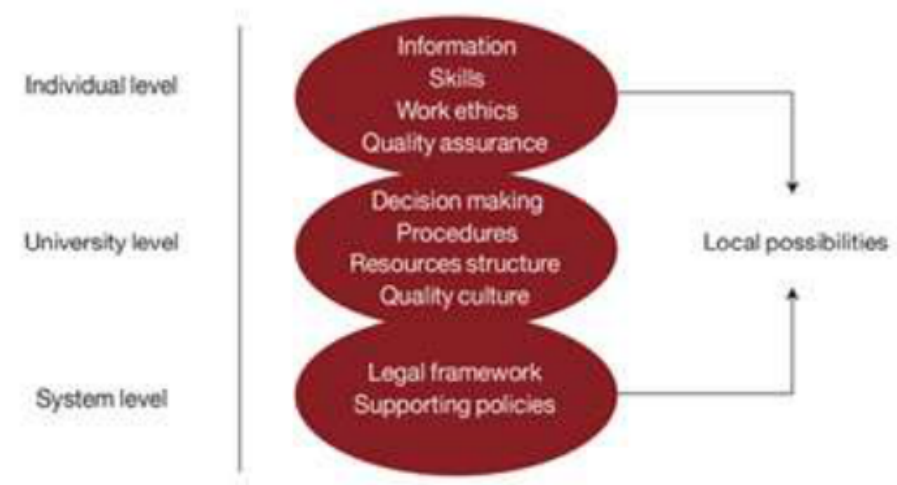

Figure (1): Capacity building levels, (Drandy \& Hawk, 2007: 14)

Capacity building in light of quality assurance and university governance criteria involves increasing the capacity of individuals and groups [29]: Analysis the environment of individuals., Determining problems needs and opportunities, Formulating strategies to deal with problems, issues, needs and opportunities related to quality assurance criteria, Designing work plans, risks and change, Using different sources effectively and continuously to apply, monitor and evaluate work plans and compliance with quality assurance criteria and adoption, Using feedback effectively for ongoing assessment and improvement. Therefore, capacity building is more comprehensive than sending teams to attend training courses, as training is an important part of it, but it is part of the treatment or intervention at the level of systems there specializes in reforming education, policies and the organizational framework under which organizations operate. At the university level, it helps in its structure and in the method of decision - making, procedures, management tools and relations among universities. At the level of individuals working in the university, emphasis is placed on building the skills, qualifications, information and attitudes of individuals necessary to work and representing them to quality assurance criteria and their application. The three levels are affected by each other. The change in a certain level affects the other level, as clarified in Figure (2). Capacity - building needs should therefore, be determined at each level. There are several models of capacity building, all of which are due to building individuals' capabilities, and universities to perform administrative functions and achieve their objectives set. The following is an applied model or "module" provided by [33] to build capacity by determining needs within a full cycle. This was one of the proposed models. Figure (2) illustrates that [29].

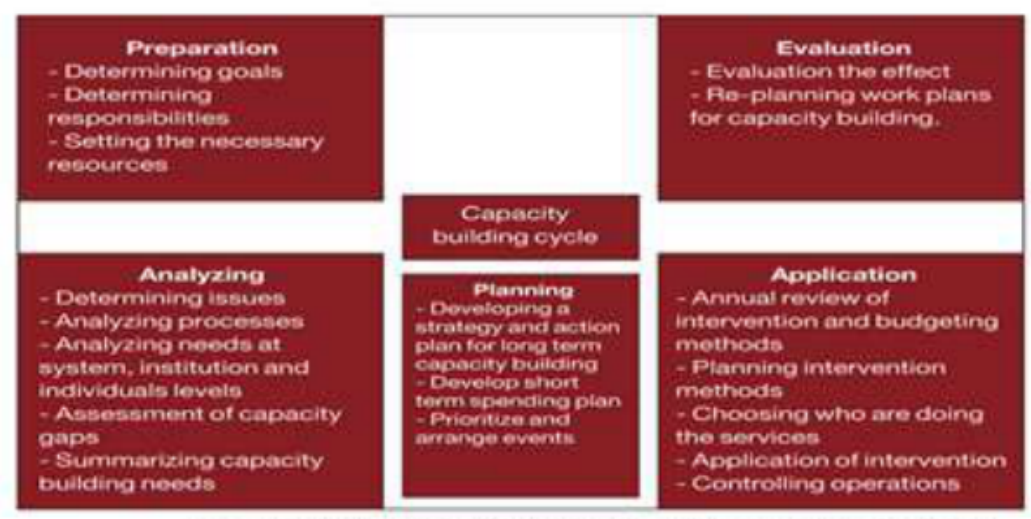

Figure (2): Capacity building çcle (Drandy \& Hawk, 2007)

Based on the above, and based on the importance of implementing the principles of governance to implement quality assurance criteria in universities, the MEU applied the 
principles of university governance in each of the eight quality assurance criteria approved by the Jordanian Higher Education Institutions Accreditation Authority and dealt with them in the form of an integrated and interactive system, as shown in Figure (3), which was called "governance as the basis of quality".

From Figure (3), it is clear that the system is a set of interdependent interrelated components that interact with one another to achieve a certain function or achieve a specific goal. The university governance system can be defined as a set of processes, activities and subsystems that ensure the leadership and administration of the university in the best way possible; in order to achieve the interests of all concerned parties. The university governance system consists of the following:

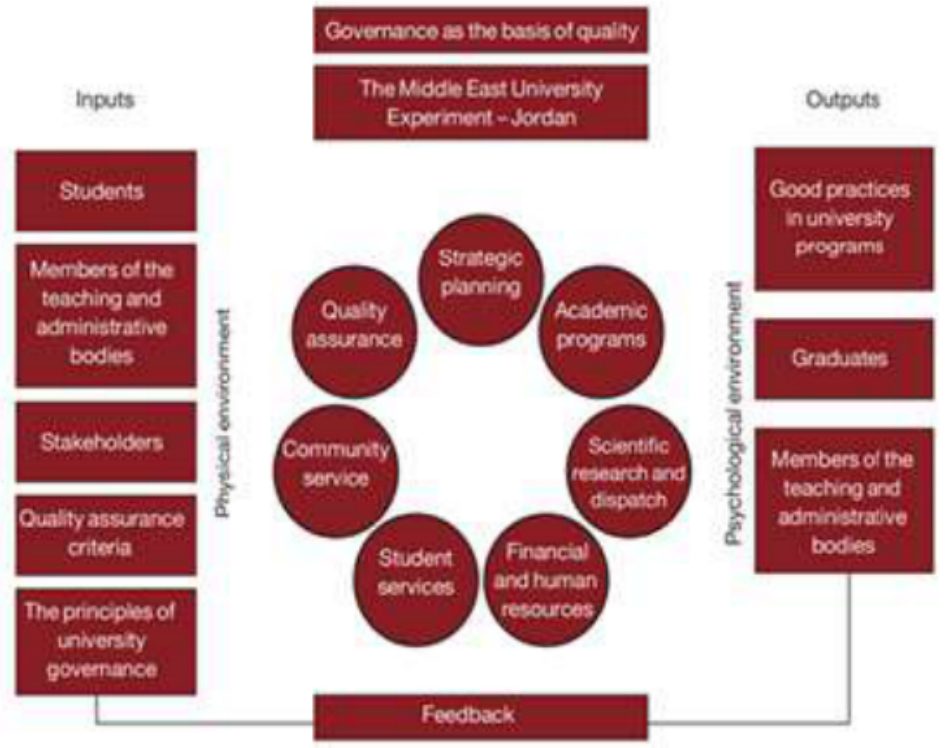

Figure (3) Governance as the basis of quality

Inputs: consists of all inputs into the system and the requirements of governance and the necessary demands.

Processes: It is intended to identify the entities responsible for implementing the governance and the supervisors of this application, with the knowledge of the control body and each administrative entity, whether inside or outside the university. Quality assurance and governance principles are key components of processes.

Outputs: Good practices include university programs, graduates, faculty members and administrators.

Feedback: is all the information that can be obtained through the processes, in addition to the positive outputs for the purpose of development enrichment, and reinforcement, as well as negative for the purpose of correction and modification.

It is worth nothing that the MEU implements the quality assurance criteria approved by the Jordanian Higher Education Accreditation Authority three years ago in order to obtain a quality assurance certificate and adopts university governance mainly in its leadership and academic and administrative operations.

Here, we must address the eight criteria adopted by the Jordanian Higher Education Institutions Accreditation Authority [22]: - Strategic planning, - Governance, - Academic programs, -Scientific research, scholarship and creativity, -Financial, physical and human resources, -Student services, -Community service and external relations, - Quality assurance. 
MEU has adopted several quality assurance components based on university governance that can be summarized as follows [34]:

- The existence of realistic goals and verifiable tasks.

- The existence of policies, systems, and mechanisms to implement access to goals.

- The existence of binding criteria in the academic, administrative, students, infrastructure and resources fields.

- The existence of benchmarks to clarify the nature and traits of study programs and degrees awarded in different disciplines.

- The existence of specific measurement systems and indicators of performance to judge policies, systems and mechanisms of implementation within the framework of objectives and tasks.

- The existence of a continuous institutional system for quality management and assurance aimed at auditing, accounting and development.

- The existence of continuous Think Tank mechanisms and centers of thought and planning for future.

- How to explain to the plan the likelihood that the evaluation program will lead to improvement of the institution when implemented.

- Is the timeline for the evaluation program realistic?

- What evidence is that the plan provides the appropriate management for the evaluation program?

The purpose of applying quality assurance criteria at the MEU is to improve the efficiency and effectiveness of the educational process, inputs, processes and outputs to meet the needs of the society and labor market requirements, and to achieve excellence in all its aspects, locally and internationally, in order to achieve excellence in all the work done by the university, and to find out the extent of commitment of the faculties of the university and its departments, centers and offices to the quality assurance criteria approved by the accreditation authority of Jordanian higher education institutions, the university has established a quality control and audit unit, which was formed by a decision of the university president, No. 104/2012-2013, on January, 2, 2013 to undertake the following tasks:

First: Check the implementation of quality criteria and quality assurance in colleges, deanships, departments, centers and offices through: -The existence of a vision, a mission, goals and plans of implementation.-The application of the mechanisms used in the development of vision, mission and goals.-Knowledge of others and their participation in the formulation of vision, mission and goals.-The procedures used in spreading the vision, mission and goals. Updating tools to measure the effectiveness of educational programs.-There are plans in the colleges to develop them in line with the mission and goals.-Policies and procedures for student development programs and student services.-Determining the characteristics of the student community and how to benefit from them.-Involvement of students in administration.Providing the student guide including the basics of acceptance, and instructions for granting the degree and study plans.-There are grounds for appointing faculty members.-Evaluating the performance of members of the administrative and teaching staff periodically.-The application of the academic freedom policy.-Developing teaching and learning methods and scientific research tools.-There are clear procedures for the scholarship process.-The effectiveness of scientific research committees at the faculty level.-The follow - up mechanisms for university students.-The mechanisms of interaction of teaching staff members with the community.Continuing coordination between faculties and the library administration to provide information and resources to students and faculty members.-Periodically updating books, 
periodicals and scientific references.-Providing modern technology methods for data exchange and information.-Reviewing budgets for the past year, and study how to achieve revenue and spend costs.-The preparation of annual budget based on the study of previous budgets in line with future plans and discussed with the finance department for adoption by the Board of Deans.-Not exceeding budget allocations in any of its items except with the approval of the finance department and the Board of Deans.-Adequate financial resources allocated.-Providing periodic and preventive maintenance policies for equipment.-The existence of plans to update and develop physical resources in line with the requirements of the development of educational programs.-Commitment of faculty members and staff to professional and ethical standards.Continuous evaluation of integrity policies and procedures.-Providing accurate, correct and consistent information through evidence.-The existence of programs, studies and services for the community.-Providing accurate information easily and delight to the community.Implementing quality assurance tools such as: policies, procedures, activities, models, files and other tools.-Developing academic programs and plans within specific quality criteria.Providing documentation for student achievement.-Providing mechanisms for receiving and dealing with student complaints and suggestions.-Providing records showing the contribution of scientific research, and the interaction of the faculty members, and the relevant authorities in the service of the community.-The efficient use and development of student database.

Second: Preparing the periodic reports and the necessary recommendations based on the extent to which quality and quality assurance criteria are met at the university for the competent authorities for the purposes of improvement and development.

\section{RECOMMENDATIONS}

Based on the importance of obtaining the universities quality certificates, whether at the national level or at the international level, and the importance of the application of governance in universities, which is an integrated system of a combination of human and physical elements integrated and interactive generate harmony and balance within the university, as the loss caused a significant imbalance in its processes and then its outputs, the researchers concluded the following:

- Promoting a culture of quality among students and all employees, as well as governance and its principles.

- The preparation of awareness programs for students and faculty members and administrative bodies, especially the new ones through seminars, lectures and workshops on quality and criteria, and on governance, its principles and areas of application.

- The need to activate university governance and its principles, especially when applying quality assurance criteria at the university.

\section{CONCLUSION}

Accordingly, for any higher education institution that plans to play a part in globalization, accreditation as a crucial feature is to aid higher education institutions to keep up with anticipated national and international standards and, at the same time, provide required academic programs to its customers. Criteria for evaluating quality of higher education have become standards. Quality assurance has become one of the most useful tools available to help higher education institutions better meet their goals. Given the study's design, the conclusions will subsidize to existing literature and future research regarding the impact of governance on higher education qualities, as well as the changes higher education institutions went through while implementing its principles. More important is that the results will afford insight into the Jordanian higher educational reform efforts and international education. 


\section{ACKNOWLEDGMENT}

The authors are grateful to Middle East University, Amman, Jordan for the financial support granted to cover the publication fee of this research article.

\section{REFERENCES}

[1] Al-Tarawnah, E, The concept of the governance of the institutions of higher education, and its purpose and ways of application, Amman, Jordan, 2010

[2] Abo - Al - Rob, A.K., Al wadi, M. \& Al - Taei, R, Quality assurance in higher education institutions: Research and studies, Amman: Dar Al-Safa for Publishing and Distribution, 2010

[3] Barkawi, B. Kharbat, F. \& Abo - Al - Rob, "Developing a framework to ensure the quality of education and learning in institutions of higher education", Arab Journal for Quality Assurance of Higher Education, (20), 2015, pp 187-207.

[4] Al-Qarni, a, "Building the internal quality system in the institutions of higher education" The First Arab International Conference for Quality Assurance of Higher Education, Zarqa University, Jordan, 2011

[5] Al-Qarni, A. Akawi, A. \& Al-Dawood, I, "King Saud University experiment in building comparative reference system", The Third Arab International Conference for Quality Assurance of Higher Education, Zaytuna University, Amman, Jordan, 2013

[6] Barkawi, B, Quality assurance in higher education: The case of the United Arab Emirates Center for Strategic Studies and Research, The United Arab Emirates, 2012

[7] Nasereddin, Y, A guide for Arab Universities Governance, A working paper for the $48^{\text {th }}$ session of the General Conference of the Union of Arab Universities, Saint Joseph University, Beirut, Lebanon, 2015

[8] CCA, Standards for Licensure and Accreditation, UAE, 2011

[9] ABET, Accreditation Policy and Procedures, USA, 2011

[10] Al-Hileh, Mohamed M. and Nasereddin, Tamara, The role of department heads in the application of quality and governance in their departments. 8th Annual Conference of the Arab Organization for Quality Assurance in Education at the American University of Beirut, Lebanon, on "Enhancing the quality of education at the regional level" during 1-2 December 2016.

[11] Nasereddin، Y. Adel, Governorship and Community Reform "A Future Outlook". British Journal of Humanities and Social Sciences 9(2), 2013, pp 23-38.

[12] Halawah, J. \& Taha, N, The reality of governance at Al-Quds University, Al-Quds University The Institute for Sustainable Development, Educational Sciences House, AlQuds, Palestine, 2011

[13] Bazawya, A. \& Salmi, A, The quality of higher education in light of achieving the principles of governance: The UK's experiment in the governance of higher education institutions, The International Forum on Governance in the Educational Institution: Evaluation of Governance Methods in Higher Education, 3-4/10/2011.

[14] Al-Sir, K.K, The application of governance in the institutions of higher education in Palestine and ways to overcome them, Islamic Educational Foundation in Gaza, Workshop on the governance of institutions of higher education, 28/3/2013.

[15] Nasereddin, Y. Adel, Governorship at the Middle East University "A Model "Community Reform "A Future Outlook". International Journal of Humanities and Social Science. 3(13), 2013, pp 156-172.

[16] Al-Taei, A. \& Hamad, A, The dimensions of local governance in Iraq: Field study in the local council for the province of Mahmudiyah, Journal of Baghdad economic college, (25), 2010, pp 41-68. 
[17] Khorsheed, M. \& Yousif, M, "The governance of institutions of higher education and strengthening the capacities of the higher education system and scientific research in Egypt, Conference on the Governance of University Education, Organized by the Arab Reform Forum at the Bibiotheca Alexandria, 2009

[18] Corcoran, Suzanne, Duty، Discretion and Conflict: University Governance and the Legal Obligations of University Boards. Australian Universities', 2004

[19] Y.A, The reality of the application of governance in the Middle East University, from the members of the teaching staff and administrative bodies' point of view, Journal of the Union of Arab Universities, No. 62 Dec. 2012.

[20] Aal Abbas, M., Governance of higher education institutions, available: 2010

[21] Shibli, M. \& Manhal, M, Building a strategic perspective on the governance system and measuring its performance. A pilot study. Al Basrah University, Faculty of Administration and Economics, Department of Business Administration, 2008

[22] Higher Education Institutions Accreditation Authority, A guide to quality assurance procedures and criteria in higher education institutions, Amman, Jordan, 2015

[23] Geuna, Aldo; Muscio, Alessandro, the Governance of University Knowledge Transfer: A Critical Review of the Literature. Minerva: A Review of Science, Learning and Policy, v47 n1, 2009, pp 93-114.

[24] Garrison, Michael Shane, Models of Academic Governance and Institutional Power in Southern Baptist Related Liberal Arts Colleges and Universities. Pro Quest LLC, Ph.D. Dissertation, the Southern Baptist Theological Seminary, 2010, 186 pp.

[25] Luescher-Mamashela, Thierry, M, From University Democratization to Managerialism: The Changing Legitimation of University Governance and the Place of Students. Tertiary Education and Management, 16 (4), 2010, p259-283.

[26] Lee, Lung-Sheng \& Land, Ming, H, What University Governance Can Taiwan Learn from the United States? Online Submission، Paper presented at the International Presidential Forum (Harbin، China), 2010, 9 pp.

[27] Lindblad, Sverker \& Lindblad, Rita Foss, Transnational Governance of Higher Education: On Globalization and International University Ranking Lists. Yearbook of the National Society for the Study of Education, v108 n2, 2009, p180-202.

[28] Slimperi, D. R., Franco, L. M., Zanten, T. V., and Maculay, C, A framework for institutionalizing quality assurance. International Journal for Quality in Health Care, 14, 2002, pp 67-73.

[29] Drandy, E. \& Hawk, T, A pilot study of the views of some officials and teaching staff members on the procedures of applying the evaluation and quality assurance processes in Saudi universities, A research presented to the $14^{\text {th }}$ Annual Conference of the Saudi Society for Psychological and Educational Sciences, (Justin), Qassim, 28-29/4/1428, 2007

[30] Lewis, R, International developments in quality assurance-are national systems of quality assurance growing together or apart? Paper presented at the First National Conference for Quality in Higher Education, Riyadh, S.A, 2007

[31] Miller, J. A., Osinski, S., and Osinski, M, Training needs assessment. International society for performance improvement. Available at: http://www.ispi.org/, 2002

[32] UNESCO UNESCO/OECD Guidelines for Quality provision in cross-border higher education. UNESCO: Division of Higher Education, Paris, 2005

[33] Rohdewohd, R. and Poppe, M, Guideline on capacity building in the regions. Module A: the capacity building cycle from capacity building needs assessment (CBNA) towards the capacity, 2005

[34] CAA, Standards for UAE's National Framework, UAE, 2012

[35] Morrison, T, Actionable learning: A handbook for capacity building through case based learning. Tokyo: Asian Development Bank Institute, 2005 
[36] Dr. S. Ravichandran, Empirical Investigation of Quality Assurance of India Software Development Organisations, International Journal of Computer Engineering and Technology (IJCET), Volume 1, Number 1, May - June (2010), pp. 147-157

\section{BIBLIOGRAPHY AUTHORS}

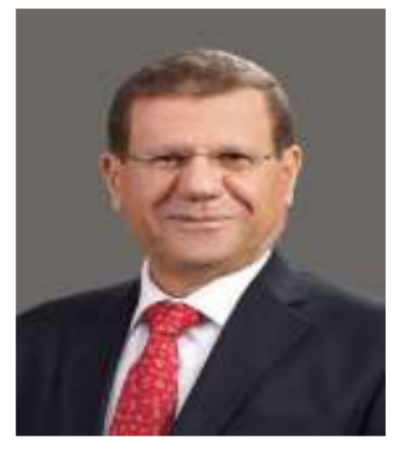

Prof. Mohammad M. Al Helih is the president of the Middle East University (MEU) at Amman- Jordan. Prior to joining the MEU on April, 2009, he was the acting president of AlIsra Private University. After receiving his Ph.D. in Educational Technology, Alheileh was assistant professor at Educational Sciences FacultyUNRWA, where he rose to the rank of full professor. He served as Dean of Educational Sciences Faculty- UNRWA for almost three years. His distinguished career spans the fields of Educational technology, Multimedia education and Instructional design. He has more than 75 publications in reputable journals, authored and co-authored 18 textbooks and has mentored more than 50 master and doctoral students. Among his awards and recognitions are the Late King Hussein Award of Distinguished Student, Abdulhameed Shoman Institution Prize for Distinguished Science Teachers ( 3 times) and Yarmouk's University Distinguished Postgraduate student ( 2 times).

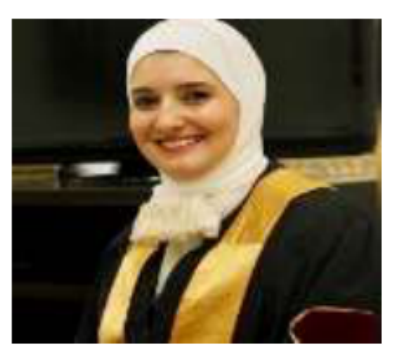

Dr. Tamara Yacoub Nasereddin is an Associate Professor at the Faculty of Law/Department of Private Law. Dr. Nasereddin held a number of administrative and academic positions, including Assistant to the President of Middle East University, the Head of Control and Inspection Unit for Quality Assurance at the University, and the Head of Department of Private Law at the Faculty of Law. She was a member of Greater Amman Municipality Committee and the Academic Committee of the Scientific Research Fund, and is currently a member of Amman Governorate Council. 